\title{
O CICLO PECUÁRIO NO BRASIL: UMA ANÁLISE USANDO A METODOLOGIA DA DINÂMICA DE SISTEMAS ${ }^{1}$
}

\author{
Raissa Carvalho Bragança \\ Newton Paulo Bueno
}

\begin{abstract}
Resumo: O objetivo deste texto foi verificar se a dinâmica do rebanho pecuário brasileiro pode ser melhor explicada por razões sistêmicas internas à economia brasileira ou por variações exógenas na demanda de carne. A conclusão obtida foi a de que, como previsto pela teoria do ciclo pecuário, razões internas ligadas a adoção do programa de estabilização econômica em 1994 foram mais importantes para explicar a estagnação do rebanho brasileiro a partir de 2000. A principal implicação de política desse resultado é que, pelo menos em teoria, existe um espaço para estabilizar a dinâmica da produção de carne brasileira por meio de políticas públicas adequadamente formuladas e implementadas. A metodologia utilizada no trabalho foi a de dinâmica de sistemas, que permite rastrear os principais ciclos de retro-alimentação responsáveis pelo ciclo pecuário e identificar eventuais pontos de alavancagem do sistema, isto é os pontos mais sensíveis aos efeitos de políticas.
\end{abstract}

Palavras-chave: Boi gordo, dinâmica de sistemas, ciclo pecuário, commodities, política econômica.

Recebido em: 09/12/2009; Aceito em: 24/06/2010.

Graduanda em Economia - UFV, Bolsista IC/FAPEMIG. E-mail: raissa_braganca@yahoo.com.br

3 Professor Associado, (Doutor/ Pós-Doutor), Departamento de Economia, UFV. E-mail: npbueno@ufv.br 


\section{Introdução}

Os mercados de commodities estão sujeitos a flutuações cíclicas em sua oferta e, consequentemente, nos preços, geralmente, devido a choques de demanda internos ou externos e à sazonalidade desses produtos ao longo do ano. Os fatores climáticos, como estiagens, alteram o período de colheita dos grãos, gerando atrasos na colheita e excesso ou escassez desses produtos. Da mesma maneira, os animais para corte são afetados por esses fatores, uma vez que o peso exigido para o abate pode ser comprometido. O resultado é a alta volatilidade dos preços das commodities, pois os produtos em determinadas épocas do ano são ofertados em abundância, gerando queda dos preços, enquanto que em outras, a oferta é mínima, levando a um acentuado aumento. No caso específico do gado de corte, tema que será estudado neste trabalho, além da sazonalidade anual, é possível identificar um ciclo pecuário endógeno (STERMAN, 2000), que se manifesta da maneira descrita abaixo.

Quando a demanda de boi gordo, por algum motivo, aumenta, os preços sobem, induzindo um maior abate de vacas. A redução no número de tais animais causará menos nascimentos de bezerros no período seguinte, acentuando a escassez de bois e de novilhas para reposição do rebanho (EMBRAPA-DID, 1981). Assim sendo, o gado tende a aumentar em épocas de desaquecimento da demanda - pois há diminuição no abate de vacas -, e a diminuir quando há um período de demanda acima do normal, gerando flutuações cíclicas na oferta de animais prontos para abate, que serão percebidas no futuro. Choques de demanda do boi gordo, em um determinado ano, poderão produzir efeitos sobre o setor durante vários períodos produtivos à frente. Para o aprofundamento deste estudo, fazse necessário entender o processo produtivo (criação, reprodução e abate) dos bovinos.

Na bovinocultura de corte, os agentes mais expressivos, segundo Michels et al. (2001), são os produtores de insumos, os de bovinos, os abatedouros e frigoríficos e a rede atacadista e varejista. Cada um desses agentes 
estabelece fluxos de troca entre consumidores e fornecedores e, também, sucessivas operações de transformação que podem ser divididas e ligadas por encadeamentos técnicos em uma linha de suprimentos. Apesar dessa divisão variar, dependendo do objetivo da análise, três macrossegmentos podem ser apontados: comercialização (empresas que entram em contato com o cliente final e viabilizam o consumo e o comércio dos produtos finais); industrialização (etapa constituída pelas firmas responsáveis pela transformação das matérias-prima em produtos finais) e, produção de matérias-prima (representados por firmas e produtores rurais que fornecem as matérias-prima iniciais ${ }^{4}$ ).

Essa cadeia produtiva gerou, em 2007, um faturamento de mais de $\mathrm{R} \$ 50$ bilhões e, aproximadamente, 7,5 milhões de empregos. No mesmo ano, segundo levantamento da Scot Consultoria, o país tinha um rebanho de mais de 197 milhões de cabeças de gado, que ocupavam 176,46 milhões de hectares com pasto, contrapondo os 221 milhões de hectares em 1993 (indicando aumento de produtividade no setor pecuário).

Esses números expressivos, contudo, não escondem o fato de que o rebanho estagnou a partir do início desta década, como mostra a Figura 1.

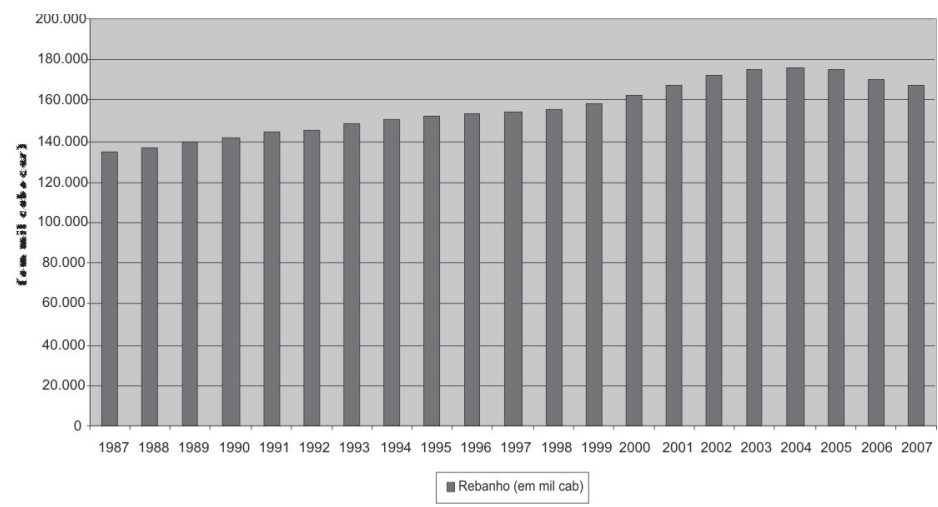

Figura 1- Brasil: Rebanho Bovino (mil cabeças)

MORVAN citado em MICHELS, I. L. Cadeia produtiva da carne bovina de Mato Grosso do Sul. Campo Grande: Editora Oeste, 2001, p. 29. 
Diversas explicações têm sido apresentadas para essa estagnação, tais como alterações ocasionadas pela fertilidade do solo, preço da terra, condições das pastagens, readequações nas relações da cadeia produtiva (MICHELS et al., 2001), ou, abate excessivo, que alimentou as exportações do período, migração (em razão do alto custo da terra) e conversão para outras opções de uso de maior rentabilidade (BUAINAIN E BATALHA, 2007).

Este trabalho oferece uma causa adicional para a estagnação e uma posterior evolução do rebanho, que reside na dinâmica endógena do ciclo pecuário. Na próxima seção, será mostrado como representar uma cadeia de produção complexa, como a do gado de corte, com o auxílio de um modelo sistêmico simples. Na seção de resultados e discussão, calibrase o modelo para as condições reais da economia brasileira e procede-se a um teste de validação, mostrando ser capaz de reproduzir com acuidade aceitável a dinâmica do setor no período considerado.

\section{Referencial Teórico}

O modelo de ciclo pecuário a ser desenvolvido na próxima subseção será construído com base na abordagem da dinâmica de sistemas. A referida abordagem (system dynamics) é uma metodologia desenvolvida para rastrear as consequências de ações isoladas sobre o comportamento de variáveis que se encontram interligadas em malhas de ciclos de retroalimentação, mas separadas no tempo e no espaço, isto é, relacionamse com defasagens temporais normalmente não captadas em nossos modelos mentais ${ }^{5}$.

A metodologia da dinâmica de sistemas pode ser definida, sinteticamente, como abordagem informação/ação/consequências, como representado na figura abaixo:

\footnotetext{
As técnicas incluídas nessa metodologia começaram a ser desenvolvidas pelo pesquisador do Massachussets Institute of Technology, Jay Forrester, nos anos 60, em uma série de estudos clássicos sobre economia regional e urbana. Têm sido empregadas em estudos aplicados em campos distintos do conhecimento, como política internacional, ecologia, gestão de recursos naturais e economia. Uma bibliografia de referência básica pode ser obtida em <http://www.systemdynamics.org/short_bibliography.htm>.
} 


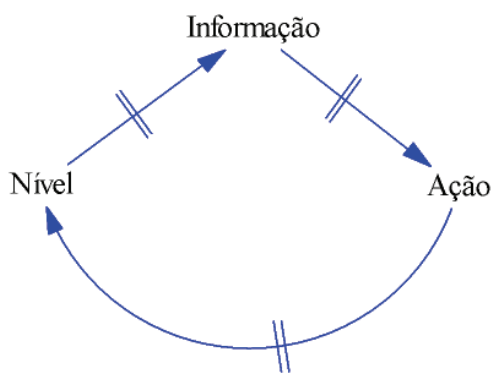

Figura 2 - Dinâmica de sistemas - abordagem informação-açãoconsequências

Ações alteram o estado (nível) das condições de um sistema após uma defasagem de tempo (as duas marcas paralelas sobre a seta indicam a existência de um intervalo entre a execução da ação e a mudança no estado do sistema). Ação, nível e informação interligam-se em dois tipos de ciclos de retroalimentação. O primeiro, negativo ou de equilíbrio, no qual o sistema reage a mudanças compensando-as. O segundo, positivo ou de autorreforço, em que o sistema amplifica eventuais perturbações.

A metodologia da dinâmica de sistemas é apropriada para examinar as questões propostas no trabalho, na medida em que permite a identificação e a análise dos ciclos de retroalimentação críticos para a dinâmica de sistemas como a da cadeia produtiva do gado de corte (CONSTANZA \& RUTH, 1998). Essa metodologia tem sido utilizada para estudar a dinâmica de uma variedade de sistemas sócioecológicos, isto é, aqueles que incluem o homem e seu meioambiente (CAVANA \& FORD, 2004; FORD, 1999), tais como agricultura irrigada (SENGUPTA et al., 2001) e reservas pesqueiras (BUENO \& BASURTO, 2009). 


\subsection{Descrição do Modelo}

Utilizando o programa VENTANA Systems (VENSIM), o modelo básico foi formalizado a partir da estrutura estoque-fluxo simplificada, apresentado na Figura 3.

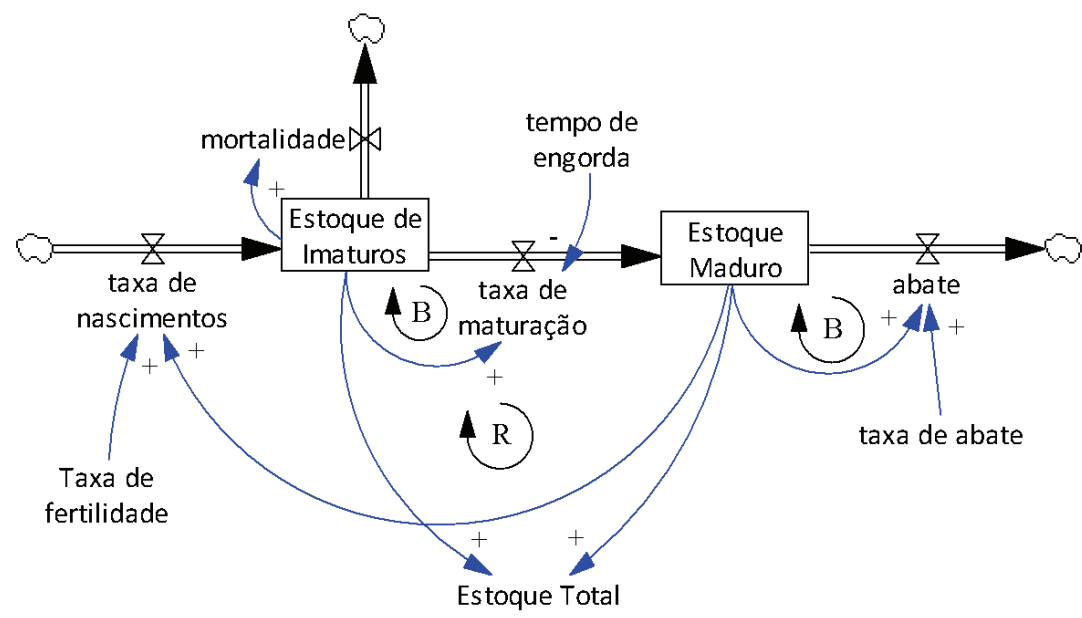

Figura 3 - Estrutura estoque-fluxo simplificada para a cadeia do gado de corte

As variáveis dentro das caixas são de estado ou de nível do sistema, enquanto as outras são ou parâmetros, como a taxa de fertilidade, ou auxiliares, como a taxa de nascimento. Esta fornecerá o número de bezerros anualmente, por isso depende do estoque de matrizes (vacas) e da taxa de fertilidade do rebanho. A taxa de abate será a porcentagem de bovinos maduros abatidos por ano, enquanto a taxa de maturação será a quantidade de bovinos imaturos que passam para o estoque maduro por ano, considerando que esta passagem é afetada pelo tempo de engorda. O sinal positivo indica a existência de uma relação direta entre as variáveis e o negativo, o oposto. Desse modo, a taxa de maturação, por exemplo, diminui com o aumento do tempo de engorda e aumenta quando o estoque 
de imaturos aumenta. A marca B indica a presença de um ciclo de retroalimentação negativo ou de equilíbrio, e, a marca $R$, indica que é positivo ou de autorreforço. Portanto, um aumento do estoque maduro aumenta a taxa de nascimentos, aumentando o estoque maduro no próximo período. Dessa maneira, quando ocorre a diminuição, a relação seguirá a mesma lógica. O sinal do ciclo, isto é, se é de autorreforço ou de equilíbrio, é obtido multiplicando-se os sinais das relações incluídas no próprio ciclo.

O efeito do ciclo de reforço é captado pela seguinte equação diferencial:

$\partial($ Estoque Maduro $) / \partial t=($ Taxa de maturação $)-($ Abate $)$

Onde:

Abate $_{t}=$ Estoque Maduro $_{t} \times$ Taxa de Abate

O que significa que a variação no tempo do estoque maduro depende da diferença entre o fluxo de maturação e o de gado abatido. Esse último, por sua vez, será a proporção do estoque bovino maduro destinado ao abate.

A dinâmica da população de bois imaturos será representada pela seguinte equação diferencial:

$\partial($ Estoque de Imaturos $) / \partial t=($ Taxa de nascimento $t)-($ Taxa de maturação $)-($ Mortalidade $)$

na qual

Mortalidade $=$ taxa de mortalidade $\mathrm{x}$ Estoque de Imaturos

e

Taxa de nascimento = Estoque maduro $\mathrm{x}$ proporção de fêmeas na população x taxa de fertilidade 
A taxa de fertilidade é um parâmetro que indica o número de bezerros, por vaca, que nascem a cada ano. Essa variável considera as condições que afetam o cruzamento dos bovinos, o clima, a estação, a qualidade e a quantidade de forragem e os demais fatores que interferem na produtividade. $\mathrm{O}$ valor adotado foi de 0,68 , significando que uma vaca pare um bezerro, em média, a cada dezoito meses. Já a taxa de nascimento no período $t$ dependerá dessa taxa de fertilidade e do total de fêmeas que estão em período fértil no estoque maduro (no modelo considera-se que o nascimento de fêmeas e de machos é equitativo, 50\%). Além disso, foi considerada uma taxa de mortalidade de $14 \%$; esse número abrange o percentual de bois imaturos que morrem antes de passar pelo processo de engorda.

Para efeito de análise do estoque total de gado no período $t$ definiu-se essa variável como:

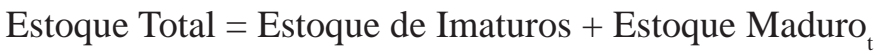

A dinâmica básica do sistema é: se muitos animais adultos são abatidos, a população sexualmente madura para reprodução diminuirá, assim como a quantidade de nascimentos nos próximos períodos. Esse é um processo que pode levar o sistema a uma escassez ou a um crescimento excessivo na oferta de gado. Ultrapassado um nível crítico de taxa de abate, pode haver um colapso devido ao ciclo de retroalimentação envolvido.

\subsection{Derivação da condição de equilíbrio do sistema}

A condição de equilíbrio do sistema é obtida igualando o fluxo de entrada no estoque de bois com o de saída. Para o caso do modelo simples acima, o fluxo de entrada é dado pela taxa de nascimento - que indicará a quantidade de bovinos que entrará na cadeia produtiva -, e o de saída, definido pela taxa de abate somada à mortalidade natural.

Os fluxos na cadeia produtiva, assumindo os valores explicitados acima para os parâmetros, são dados por: 
e

Abate = Estoque Maduro $\times$ taxa de abate

Igualando a variável de fluxo de entrada com a soma das variáveis do de saída, obtém-se então:

Toxa de nascimentos $=($ Mortalidade $)+($ Abate $)$

$\mathrm{Ou}$

(Estoque Maduro $\times 0.5 \times$ Taxa de Fertilidade)

= (Estoque Maduro $\times$ Taxa de Mortalidade)

Substituindo-se os valores dos parâmetros na equação, obtém-se:

Taxa de Abate $=0.5 \times$ Taxa de Fertilidade

Isso significa que o sistema estará em equilíbrio quando a taxa de fertilidade for o dobro da de abate. Se considerarmos, para simplificar, uma taxa de fertilidade de 0,5 - valor razoável para o rebanho brasileiro antes da estabilização econômica -, ou seja, que a cada dois anos nasça um bezerro, a taxa de abate que equilibrará o sistema será de 0,25. 


\subsection{O procedimento de calibragem}

Calibrar um modelo significa encontrar os valores das constantes que geram trajetórias das variáveis endógenas, sendo os que melhor se ajustam aos dados reais correspondentes. Embora a calibração possa, em princípio, ser feita manualmente (reduzindo os erros entre valores simulados e reais para cada variável), o VENSIM permite fazer, automaticamente, modelos complexos com grande número de variáveis endógenas e parâmetros.

Esse procedimento consiste em determinar a combinação de parâmetros que minimiza o erro entre os valores simulados e os observados das variáveis de controle do modelo sistêmico construído. Isto é, minimiza $\sum_{i=1}^{j} w_{i}\left(Y_{i}^{e}-Y_{i}^{r}\right)^{2}$, onde $\mathrm{j}$ e $\mathrm{w}_{\mathrm{i}}$ são, respectivamente, o número de variáveis a serem calibradas e a ponderação com que cada uma entra na função de payoff, de modo que não seja dado, no processo, peso maior às variáveis com maior dimensão absoluta.

O presente modelo foi calibrado de modo a minimizar o erro (quadrado) entre as séries de valores estimados e observados no Estoque Maduro de Boi Gordo. Os parâmetros, que serão utilizados nas próximas seções, são as taxas de fertilidade, de mortalidade e de abate. 


\section{Resultados}

\subsection{Teste de Validação do Modelo}

Os valores dos parâmetros ainda não definidos assumidos nas simulações para o modelo calibrado são apresentados na Figura 4.

\begin{tabular}{|c|c|}
\hline Taxa de abate & $15.5 \%-1987 / 1996 ; 23.5 \%-1997 / 2007$ \\
\hline Tempo de engorda & 5 anos 1987/1996; 3 anos- 1997/2007 \\
\hline
\end{tabular}

Figura 4 - Valores de parâmetro para as simulações da oferta de gado de corte

Os valores da Figura 4 são baseados em dados da Empresa Brasileira de Pesquisa Agropecuária (EMBRAPA) e Anuário da Pecuária Brasileira (ANUALPEC) (média simples). Para o tempo de engorda, foi considerado que este caiu de 5 anos em 1978 para 3, a partir de 1997.

O objetivo da simulação é mostrar como um modelo sistêmico simples, devidamente calibrado, pode imitar a dinâmica complexa do ciclo pecuário. A Figura 5 mostra a taxa de abate simulada, calibrada com referência na de abate observada no período de 1987 à 2007, em porcentagem do estoque maduro total de gado por ano. 


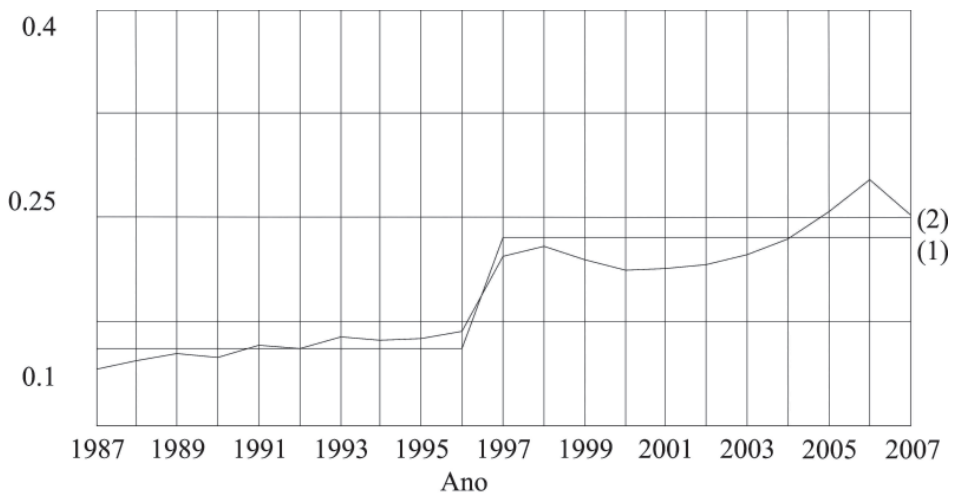

(1) taxa de abate modelada:

(2) taxa de abate real :

Figura 5 - Taxa de abate real de gado bovino e taxa de abate modelada

A Figura 6 indica que o modelo simplificado, calibrado pelos parâmetros apresentados e pelo procedimento apresentado em 2.3, pode ser considerado como uma representação da realidade da dinâmica do rebanho bovino no Brasil.

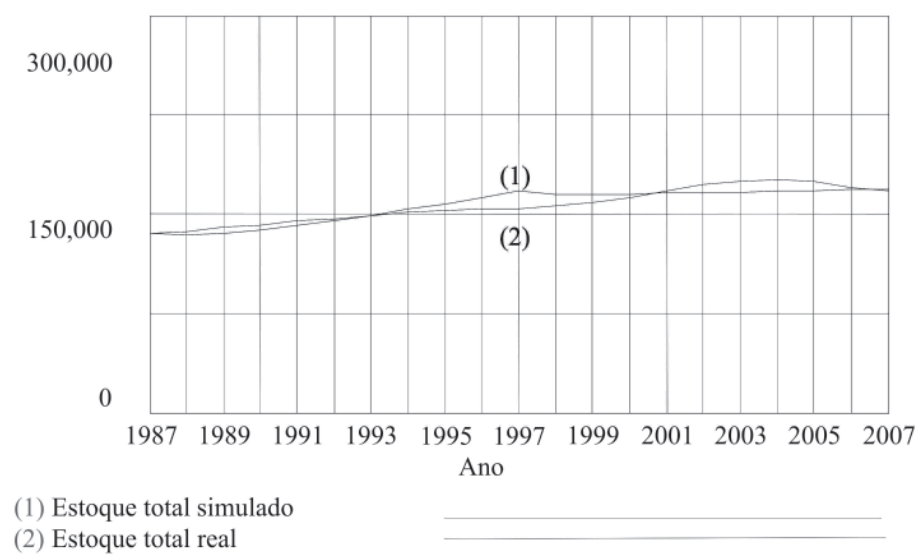

Figura 6 - Estoque Real do Rebanho Bovino x Estoque Simulado, por meio do modelo sistêmico, em mil cabeças.

Fonte: Dados da pesquisa. 


\subsection{Efeito da Estabilização Econômica sobre o Ciclo Pecuário}

A Figura 7 mostra o efeito da estabilização econômica sobre o ciclo pecuário no Brasil. A partir de 1996, a taxa de abate eleva-se como efeito da maior demanda interna de carne trazida pela estabilização econômica, elevando o poder aquisitivo médio real das camadas mais pobres da população. O aumento da taxa reduz o Estoque Maduro, isto é, a quantidade de vacas em idade reprodutiva. O número de bezerros nascidos diminuirá, reduzindo, futuramente, a quantidade de vacas em idade reprodutiva. Esse é o efeito do ciclo de retroalimentação R operando no modo decrescente. Em algum momento, o fluxo de bezerros nascidos será menor do que o número de bois abatidos, implicando na redução do Rebanho Total. Esse ponto de virada (tipping point) é ultrapassado, aproximadamente em 2004.

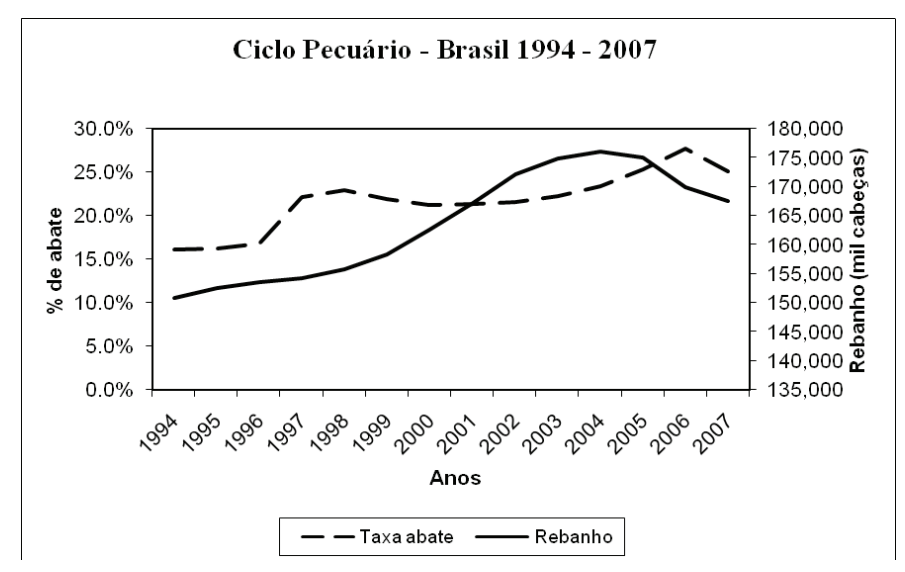

Figura 7- Taxa de abate e rebanho bovino total. 1994-2007

Pode-se avaliar o efeito da estabilização econômica sobre a evolução do rebanho bovino brasileiro, comparando-se ao cenário realmente ocorrido, que teria acontecido se a taxa de abate não houvesse se elevado com a estabilização. A Figura 8 compara esses cenários, mostrando que o rebanho 
bovino seria aproximadamente $60 \%$ maior se não tivesse ocorrido a estabilização econômica em 1994. No cenário 1 temos o estoque simulado incluindo efeitos da estabilização; no 2, o estoque teórico caso não tivesse ocorrido a estabilização econômica a partir de 1994.

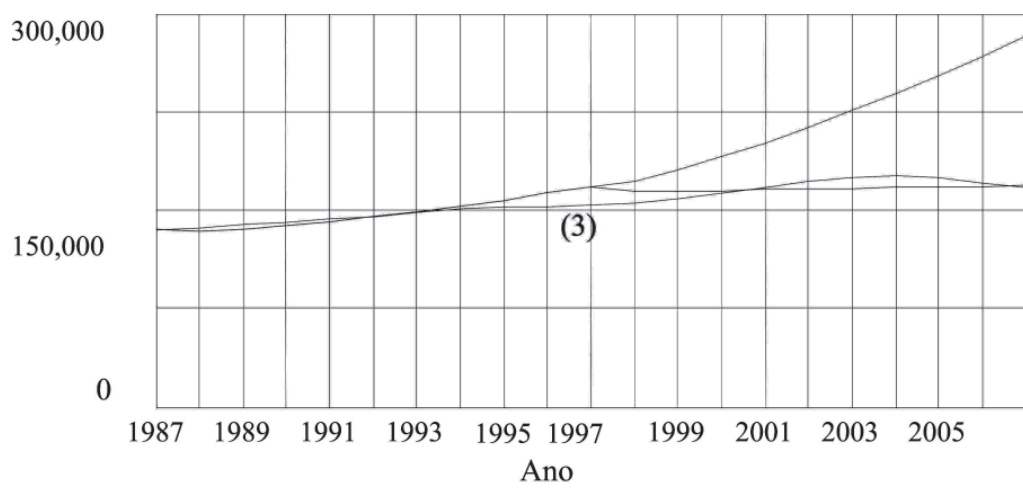

(1) Estoque Total Simulado: com estabilização

(2) Estoque Total Simulado : sem estabilização

(3) Estoque total real:

Figura 8 - Efeito da estabilização sobre o rebanho bovino nos dois cenários, (1000 cabeças)

Fonte: Dados da pesquisa.

\subsection{Efeitos de Políticas}

Indicadores recentes têm mostrado que, principalmente, graças à difusão de sistemas de manejo mais eficientes, como a adoção de duas montas anuais, o emprego de técnicas de inseminação artificial e o desenvolvimento de pesquisas genéticas (que aumentam a taxa de fertilidade), os efeitos negativos sobre a produção gerados pelo ciclo pecuário endógeno clássico, descrito neste trabalho, começaram, recentemente, a perder força. Se confirmar essa tendência, como sugerido 
na Figura 9, abre-se, teoricamente, espaço para um crescimento mais vigoroso do rebanho e dos abates que poderia, em princípio, sustentar a expansão das exportações de carne prevista para os próximos anos.

Rebanho Total

(1000 cabeças)

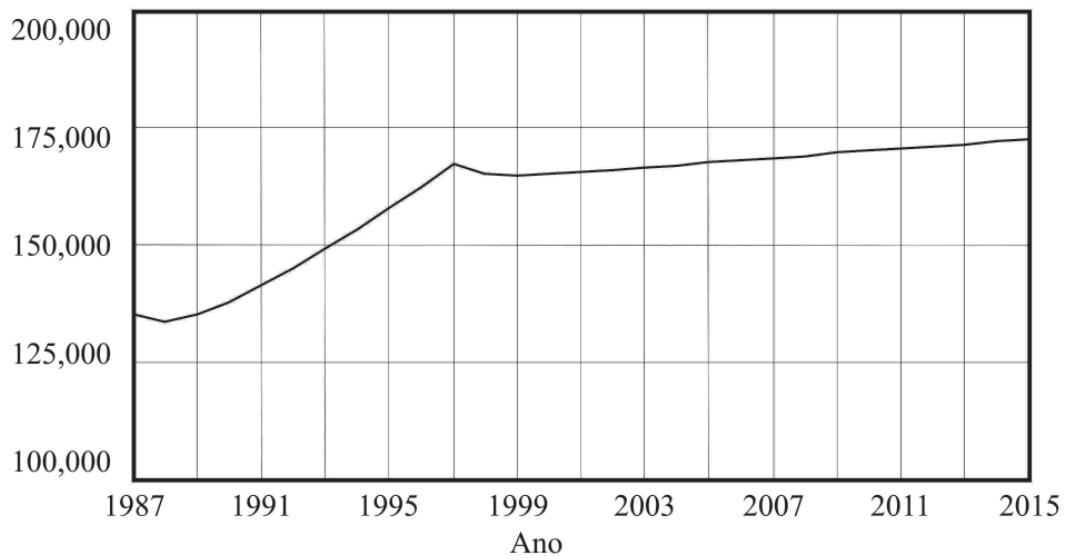

Figura 9 - Evolução da dinâmica do rebanho, segundo o cenário do ciclo pecuário clássico

Fonte: Dados da pesquisa.

Com o crescimento das exportações nos últimos anos, uma nova manifestação do ciclo pecuário tem se tornado visível, e tende, provavelmente, a acentuar com a manutenção do crescimento das exportações para países em desenvolvimento, principalmente para a China. A tendência do abate de fêmeas, para aproveitar as oportunidades especialmente boas do mercado internacional de carne, poderá comprometer o crescimento do rebanho e dos abates nos próximos anos (BUAINAIN E BATALHA, 2007). A Figura 10 esboça a dinâmica esperada do rebanho até 2015 , supondo uma redução de $10 \%$ na proporção anual de fêmeas em idade reprodutiva. 


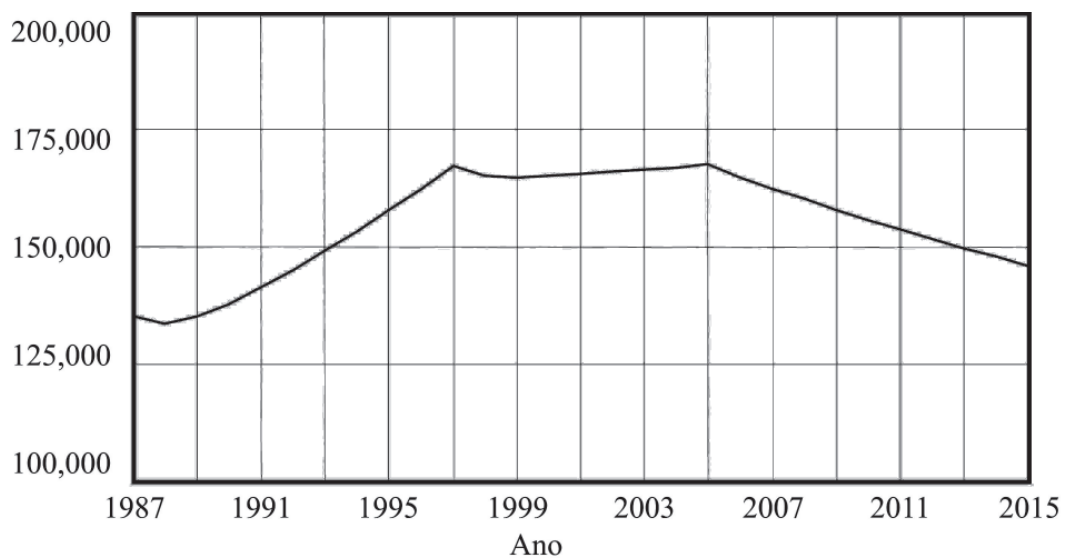

Figura 10 - Evolução estimada do rebanho bovino com manutenção de tendência de abate de fêmeas / Rebanho Total / (1000 cabeças)

Fonte: Dados da pesquisa

É importante indagar se esta última tendência, elevar o abate de fêmeas, pode ser compensada pela intensificação dos processos de melhoria das características dos rebanhos descritas no início desta seção. No painel a seguir (Figura 11), testa-se a sensibilidade da dinâmica do rebanho bovino a oscilações nessas variáveis e esses resultados são comparados à sensibilidade da dinâmica do rebanho ao abate de fêmeas (que reduz o estoque em idade reprodutiva). 

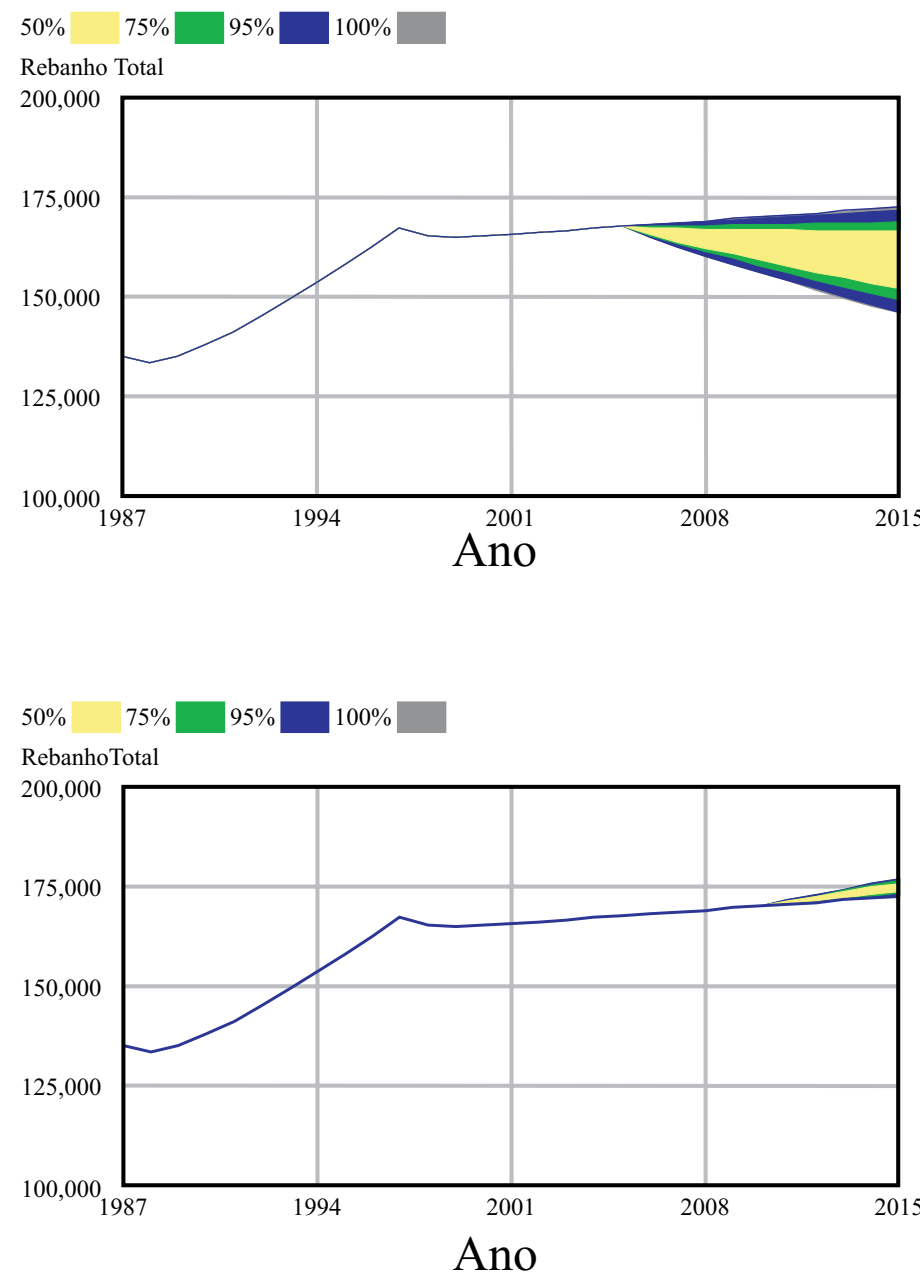

Sensibilidade da dinâmica à proporção de fêmeas / Sensibilidade da dinâmica à redução da taxa de mortalidade 

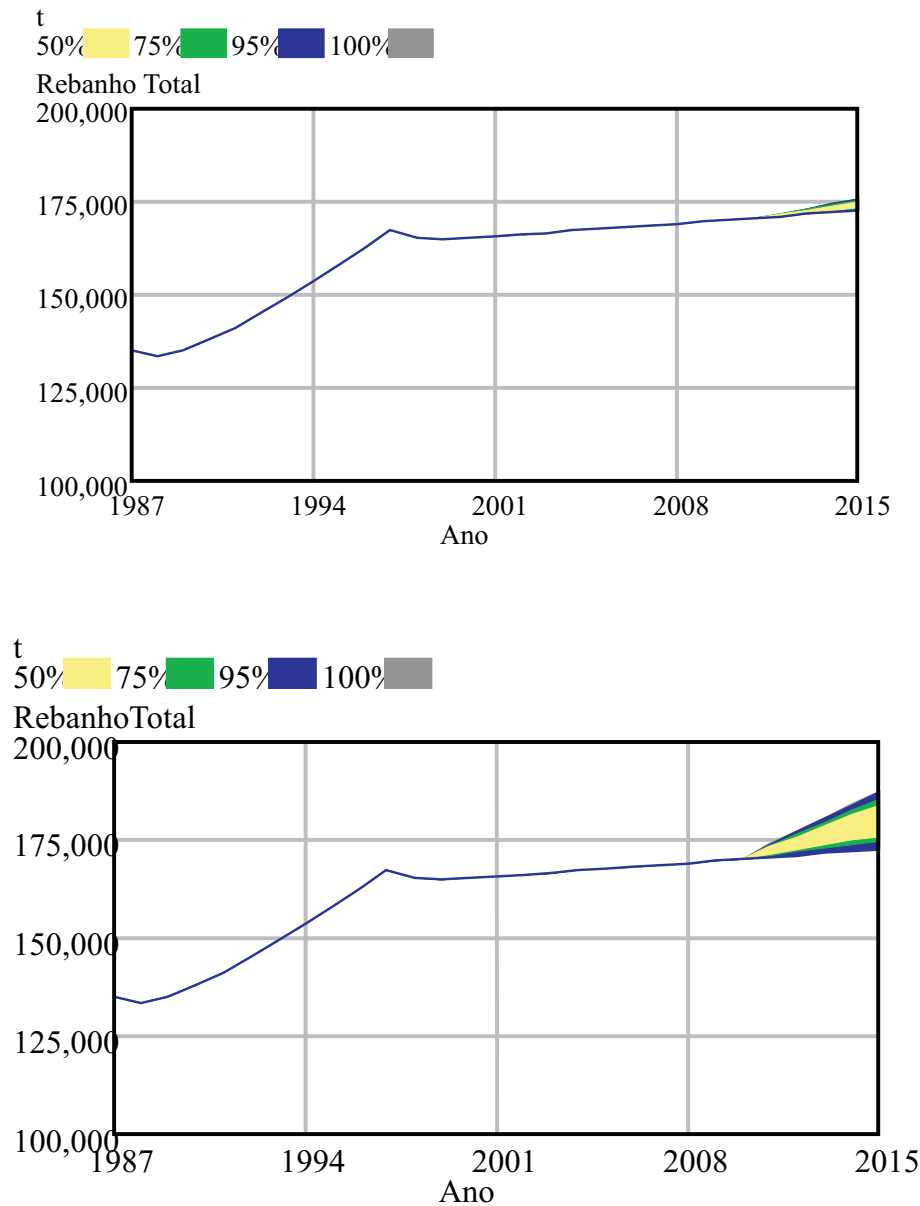

Sensibilidade da dinâmica à redução do tempo de engorda / Sensibilidade da dinâmica em relação à taxa de fertilidade

Figura 11 - Painel de teste das sensibilidades Fonte: Dados da pesquisa. 
Os gráficos mostram os intervalos de confiança para as alterações da variável dependente: rebanho total em resposta às variações nos parâmetros (proporção de fêmeas no rebanho, taxa de mortalidade de novilhas, tempo de engorda e taxa de fertilidade). Técnicas de manejo mais eficientes reduzem a taxa de mortalidade e o tempo de engorda; pesquisas em melhorias genéticas aumentam a taxa de fertilidade. Os gráficos indicam que apenas um incremento substancial nesse último parâmetro é capaz de, potencialmente, compensar a tendência de abate de matrizes, ou seja, com o aumento da taxa de fertilidade, o que requer uma intensificação da pesquisa genética, talvez inalcançável a curto prazo. Como resultado, é imprescindível reduzir o abate de fêmeas para assegurar um crescimento do rebanho capaz de sustentar o crescimento previsto e desejável das exportações de carne bovina no futuro próximo.

\section{Conclusão}

Uma das principais descobertas da teoria sistêmica é que grande parte dos problemas, que ocorrem nos tipos de sistemas, possuem origem endógena. Assim, por exemplo, a volatilidade na produção de commodities deve-se, essencialmente, ao fato de que existe um ciclo inerente à produção desse tipo de bem, que decorre da presença de atrasos temporais significativos em elos de suas cadeias produtivas. A persistência de ciclos endógenos nessas indústrias, por outro lado, indica que o processo de aprendizagem e as forças de mercado, que poderiam estabilizá-los, são fracos, pois o mecanismo de preços é insuficiente para gerar os processos de retroalimentação negativa requeridos. Sabe-se que as dificuldades enfrentadas pela economia brasileira na primeira metade do século 20 ocorreram porque o café exibe um ciclo desse tipo, o qual foi amplificado pela ação governamental de tentar suprimi-lo por meio da aquisição dos excedentes produzidos. $\mathrm{O}$ que se procurou mostrar neste trabalho foi que a cadeia produtiva do boi gordo, como a de outras commodities, está igualmente sujeita a um ciclo endógeno. 
Esse ciclo tem assumido uma nova forma nos últimos anos, cujo principal fator impulsionador é o crescente abate de fêmeas para atender o crescimento das exportações. As simulações realizadas sugerem que se não forem adotadas políticas para reduzir o abate de fêmeas, não será possível atender, já em um futuro próximo, o aumento previsto de exportações devido ao crescimento insuficiente do rebanho. Além de medidas que aumentem o controle sanitário do rebanho e permitam uma rastreabilidade confiável da carne exportada (fatores indispensáveis para conquistar mercados em países desenvolvidos) são necessárias, ainda, políticas capazes de assegurar um crescimento compatível dos rebanhos, para manter a participação de nossas exportações para países em desenvolvimento. Crescimento este, atualmente, ameaçado pela amplificação dos efeitos do abate de matrizes pela dinâmica do ciclo pecuário endógeno.

\section{Referências}

BUAinain, M.; BATAlha, M. O. [Coordenadores] Cadeia produtiva da carne bovina. Ministério da Agricultura, Pecuária e Abastecimento, Secretaria de Política Agrícola, Instituto Interamericano de Cooperação para a Agricultura. Brasília: IICA: MAPA/SPA, 2007. $86 \mathrm{p}$.

BUENO, N. P.; BASURTO, X. Resilience and collapse of artisanal fisheries: a system dynamics analysis of a shellfish fishery in the Gulf of California, Mexico. Sustainability Science, v. 4 (2), October, 2009.

CAVANA, R.; FORD, A. Environmental and resource systems: An editor's introduction, System Dynamics Review. 20, 2, p.89-98. 2004.

COSTANZA, R.; RUTH, M. Using dynamic modeling to scope environmental problems and build consensus. Environmental Management. 1998. 22(2): p. 183-195. DOI: 10.1007/s002679900095 
EMPRESA BRASILEIRA DE PESQUISA AGROPECUÁRIA. Embrapa Gado de Corte. Disponível em: 〈www.cnpgc.embrapa.br〉.

FNP Consultoria e Comércio. ANUALPEC: Anuário da pecuária brasileira, São Paulo, 1996.

FNP Consultoria e Comércio. ANUALPEC: Anuário da pecuária brasileira, São Paulo, 2007.

FORD, A. Modeling the environment, an introduction to system dynamics models of environmental systems. Washington DC: Island Press, 1999.

INSTITUTO BRASILEIRO DE GEOGRAFIA E ESTATÍSTICA. Censo Agropecuário. Disponível em: http://www.sidra.ibge.gov.br/bda/acervo/ acervo2. $a s p$ ? $=\mathrm{v} \& \mathrm{p}=\mathrm{CA} \& \mathrm{z}=\mathrm{t} \& \mathrm{o}=22$.

MICHELS, I. L.; SPROESSER, R. L.; MENDONÇA, C. G. Cadeia produtiva da carne bovina de Mato Grosso do Sul. Campo Grande: Editora Oeste, 2001.

SENGUPTA, N.; SWATI, S.; OSTROM, E. Sustainability, equity, and efficiency of irrigation infrastructure. In: Constanza, R. Institutions, ecosystems, and sustainability. Boca Raton: Lewis Publishers, 2001.

STERMAN, J. Business Dynamics. Boston: Irwin McGraw-Hill, 2000.

VENTANA SYSTEMS. User's guide. 2005. 
Abstract: The purpose of the paper was to study if the dynamics of the Brazilian cattle stocks can be better explained by systemic endogenous factors or either by exogenous changes on beef demand. The conclusion, as proposed by the theory of the cattle cycle, was that systemic factors related to the adoption of the stabilization program in 1994 were apparently more important in explaining the stagnation of the Brazilian herd since 2000. The main policy implication of this conclusion is that it seems to have a space for stabilizing de dynamics of the system through adequate public policies. The methodology used was system dynamics which allows to trace the critical feedback loops that drive de cattle cycle and to identify possible leverage points in the system, defined as points in which intervention could produce maximal effects.

Keywords: Cattle, system dynamics, cattle cycle, commodities, economic policy. 